\title{
Orientation-Induced Redox Isomerism in Planar Supramolecular Systems
}

\author{
Sofiya L. Selektor, ${ }^{* \dagger}$ Alexander V. Shokurov, ${ }^{\dagger}$ Vladimir V. Arslanov, ${ }^{\dagger}$ Yulia G. Gorbunova, ${ }^{\dagger,}$ \\ Kirill P. Birin, ${ }^{\dagger}$ Oleg A. Raitman, ${ }^{\dagger}$ Fabien Morote, ${ }^{\S}$ Touria Cohen-Bouhacina, ${ }^{\S}$ \\ Christine Grauby-Heywang, ${ }^{\S}$ and Aslan Yu. Tsivadze ${ }^{\dagger, \dagger}$
}

${ }^{\dagger}$ A.N. Frumkin Institute of Physical Chemistry and Electrochemistry of Russian Academy of Sciences, Leninsky pr., 314 Moscow, 119071 Russia

${ }^{\ddagger}$ N.S. Kurnakov Institute of General and Inorganic Chemistry of Russian Academy of Sciences, Leninsky pr., 31 Moscow, 119991 Russia

${ }^{\S}$ Laboratoire Ondes et Matière d'Aquitaine (LOMA), Université de Bordeaux, UMR CNRS 5798, 351 cours de la Libération, 33405 Talence Cedex, France

\begin{abstract}
In this work, a previously undescribed phenomenon of orientation induced redox isomerism in a Langmuir monolayer is revealed in the case of cerium bis [tetra ( 15 crown 5) phthalocyaninate $]\left(\mathrm{Ce}\left[(15 \mathrm{C} 5)_{4} \mathrm{Pc}\right]_{2}\right)$. It was established that intramolecular electron transfer (IET) from the electronic system of phthalocyanine to the $4 f$ orbital of cerium atom occurs upon spreading of a $\left(\mathrm{Ce}\left[(15 \mathrm{C} 5)_{4} \mathrm{Pc}\right]_{2}\right)$ chloroform solution onto the air-water interface $\left(3 \mathrm{D} \rightarrow 2 \mathrm{D}\right.$ IET). This process is related to the transformation of $\mathrm{Ce}^{4+}$ cation in the solution to $\mathrm{Ce}^{3+}$ in the monolayer. It was also found that reversible $\mathrm{Ce}^{3+} \leftrightarrow$ $\mathrm{Ce}^{4+}$ IETs occur upon compression $\left(\pi_{1} \rightarrow \pi_{2}\right)$ and expansion $\left(\pi_{2} \rightarrow \pi_{1}\right)$ of monolayer $\left(2 \mathrm{D}^{\pi 1} \leftrightarrow 2 \mathrm{D}^{\pi 2} \mathrm{IET}, \pi\right.$ surface pressure). The mechanism of genuine redox isomerism was confirmed by the results of in situ UV-vis spectral measurements performed on monolayers and Langmuir-Blodgett films, AFM, and XPS studies of Langmuir-Blodgett films transferred at different surface pressures. The understanding of this reversible IET mechanism is especially important due to possible applications of such redox isomeric systems in the development of nanoscale multibit information storage devices.
\end{abstract}

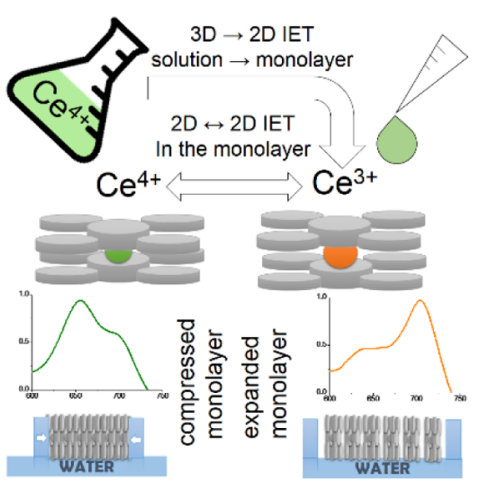

\section{INTRODUCTION}

Molecular scale systems that exhibit intramolecular electron transfer (IET) induced by various external stimuli occupy a special place among the systems whose behavior is determined by charge transfer processes. Such redox isomeric materials are indeed promising for applications in the development of nanoscale information storage devices. Research in this field has been conducted with increasing intensity in various aspects related to the design, the synthesis, and the study of new compounds with different paths of IET (metal-metal, metalligand, ligand-ligand) as well as the search for new efficient methods of inducing such reversible transitions. ${ }^{1-11}$ Currently, the most widely used ways of IET control involve micro environment (i.e, solvents), thermal, and photophysical effects. Furthermore, the action of these driving forces are investigated mainly in the case of dispersed molecular systems (solu tions) $)^{2-4,12}$ and crystals. ${ }^{3,4}$ Only a few works are devoted to the study of IET in aggregated molecules (including liquid crystals). ${ }^{5,6,13}$

In systems characterized by the coexistence of two redox isomers of the same compound, we can suppose that not only driving forces listed above (light, temperature, microenviron ment), but any physical effect that even slightly affects the internal energy of the system can shift the dynamic equilibrium toward the predominance of one of the isomers. The present work is devoted to the study of such physical effects that accompanies $3 \mathrm{D}-2 \mathrm{D}$ transition of discotic molecules as well as phase transitions in $2 \mathrm{D}$ systems.

Complexes in which both metal and ligand are redox active are target objects for the implementation and the study of redox isomerism phenomenon (reversible intramolecular metal-ligand electron transfer). From this standpoint, tetrapyrrole complexes of metals with variable oxidation states are one of the most promising compounds. ${ }^{14}$ Moreover, the ability of the metal ion in such complexes to change its valent state can be tuned by the introduction of peripheral substituents of different nature into phthalocyanine ring. ${ }^{15}$ Substituents can also drastically affect the electrochemical and optical properties of the materials based on these compounds. For example, the introduction of crown ethers into phthalo cyanine leads to novel efficient photorefractive materials and components of nonlinear optics. ${ }^{16-20}$ Such unique features of 


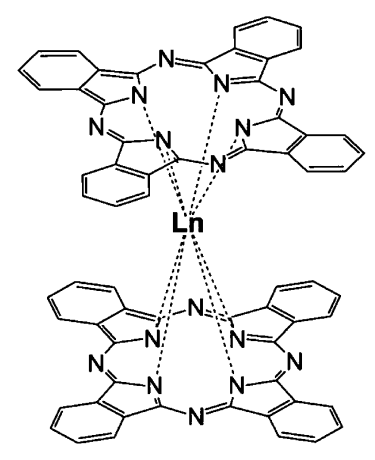

a

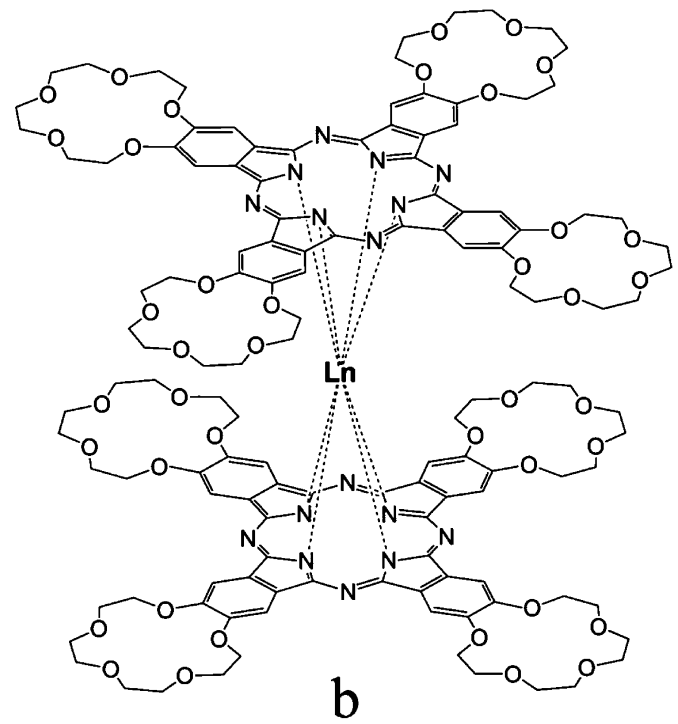

Figure 1. Structures of (a) nonsubstituted lanthanide bis phthalocyaninate $\left(\mathrm{LnPc}_{2}\right)$ and (b) lanthanide bis [tetra (15 crown 5) phthalocyaninate] $\left(\operatorname{Ln}\left[(15 \mathrm{C} 5)_{4} \mathrm{Pc}\right]_{2}\right)$.

crown phthalocyaninates result from the ability of these building blocks for supramolecular assembling facilitated by presence of crown ether moieties in the molecule. ${ }^{21-24}$

The special emphasis on lanthanide phthalocyaninate series is related to the existence of correlations between the molecular characteristics of these complexes and their physicochemical properties. ${ }^{25-30}$

In this study, we are more particularly interested in complexes incorporating cerium atom. Indeed, the key feature of cerium atom in the lanthanide series is its ability to exist in two stable valent states. Besides oxidation number $3+$ usual for other representatives of lanthanide series, it can exhibit 4+ oxidation number that is derived from a particular stability of its $4 \mathrm{f}^{0}$ electronic state. ${ }^{15,31-35}$ The coexistence of cerium complexes with tetrapyrrole ligands in two neutral forms (two redox isomers) that differ by the valent state of the cerium atom (III/IV) and the corresponding charge of the ligands was described earlier. $15,34,35$

Unusual physicochemical and electrochemical properties of cerium bis [tetra (15 crown 5) phthalocyaninate] (Ce $\left[(15 \mathrm{C} 5)_{4} \mathrm{Pc}\right]_{2} ;$ Figure 1$)$ in comparison with other rare earth element complexes have been described recently in solution, Langmuir monolayers and Langmuir-Blodgett (LB) films. ${ }^{34,36}$ In particular, changes in the UV-visible spectra of $\mathrm{Ce}$ $\left[(15 \mathrm{C} 5)_{4} \mathrm{Pc}\right]_{2}$ monolayers that can be hypothetically attributed to IET were observed. ${ }^{37,38}$ Nevertheless, theoretical under pinning and experimental proofs are not available to confirm this hypothesis. In this context, a better understanding of the mechanisms inducing such changes (which could be the first example of orientation induced redox isomerism) could allow to control the physical process and the subsequent rational design of information storage materials. Herein we combined different complementary methods to study the behavior of the $\mathrm{Ce}\left[(15 \mathrm{C} 5)_{4} \mathrm{Pc}\right]_{2}$ complex organized in Langmuir monolayers as well as in LB films transferred at different surface pressures. We give experimental proofs of this IET and describe the driving forces inducing this transfer occurring at the air-water interface in highly ordered planar monolayers of $\mathrm{Ce}\left[(15 \mathrm{C} 5)_{4} \mathrm{Pc}\right]_{2}$.

\section{EXPERIMENTAL SECTION}

The synthesis of double decker lanthanide bis [tetra (15 crown 5) phthalocyaninates $] \mathrm{Ce}\left[(15 \mathrm{C5})_{4} \mathrm{Pc}\right]_{2},{ }^{34} \mathrm{Pr}$ $\left[(15 \mathrm{C} 5)_{4} \mathrm{Pc}\right]_{2},{ }^{39} \mathrm{~Tb}\left[(15 \mathrm{C} 5)_{4} \mathrm{Pc}\right]_{2},{ }^{40,41} \mathrm{Yb}\left[(15 \mathrm{C5})_{4} \mathrm{Pc}\right]_{2}{ }^{42}$ and $\mathrm{Lu}\left[(15 \mathrm{C} 5)_{4} \mathrm{Pc}\right]_{2}{ }^{43}$ and unsubstituted $\mathrm{CePc}_{2}{ }^{37}$ was performed according to previously described procedures.

Lanthanide phthalocyaninate complexes were solubilized at a concentration in the range of $1.0-1.6 \cdot 10^{-5} \mathrm{M}$ in $\mathrm{CHCl}_{3}$ (extrapure grade), which was preliminarily dried over anhydrous $\mathrm{CaCl}_{2}$ and distilled over $\mathrm{CaH}_{2}$. Ultrapure water (18 $\mathrm{M} \Omega \mathrm{cm}, \mathrm{pH}$ 5.6) deionized with a Vodolei apparatus (NPP Khimelektronika) was used as subphase. Studied solutions were applied to the air-water interface using a Distriman micropipet (Gilson) in $5 \mu \mathrm{L}$ portions. The time of solvent evaporation and the monolayer compression rate were $15 \mathrm{~min}$ and $0.2 \mathrm{~mm} / \mathrm{s}$, respectively.

Monolayer compression isotherms were recorded using a KSV mini trough (Finland) made of Teflon and equipped with polyacetal barriers. Monolayer surface pressure was measured using a platinum Wilhelmy plate at a constant temperature of $20 \pm 1{ }^{\circ} \mathrm{C}$.

Ultrathin films on solid substrates were obtained using the standard LB procedure: the monolayer was compressed to the required surface pressure, which was then kept constant. The substrate, previously immerged into the subphase perpendicu larly to the air-water interface, was removed from the subphase at a constant rate of $5 \mathrm{~mm} \cdot \mathrm{min}^{-1}$. The nature of the substrate depended on the following method of film characterization (see below for each method), but all substrates were hydrophilic.

Absorption spectra of monolayers on aqueous subphase were recorded in the wavelength range of $240-750 \mathrm{~nm}$ using an AvaSpec 2048 FT SPU fiber optic spectrophotometer. UV-vis reflectometric probe with a fiber diameter of $400 \mu \mathrm{m}$ combined with a six fiber irradiating cable was located perpendicularly to the subphase surface at a distance of $2-3 \mathrm{~mm}$ from the monolayer. The signal obtained upon light reflection from the subphase surface immediately before the monolayer spreading was used as baseline. This method allowed us to obtain UV-vis spectra of monolayers with intensity and resolution high 
enough to distinguish even minor spectral changes. This technique was described in details elsewhere. ${ }^{44}$

Absorption spectra of LB films on quartz substrates were measured in the wavelength range of $200-900 \mathrm{~nm}$ using a Shimadzu 2450 PC spectrophotometer (Japan).

$\mathrm{X}$ ray photoelectron spectroscopy (XPS) measurements of LB films transferred onto quartz substrates were performed using a LAS 3000 instrument (Riber, France) equipped with an OPX 150 semispherical retarding field analyzer. Photoelectrons were excited by $\mathrm{X}$ rays of an aluminum anode $\left(\mathrm{ALX}_{\alpha}=1486.6\right.$ $\mathrm{eV}$ ) at a tube voltage of $12 \mathrm{kV}$ and an emission current of 20 $\mathrm{mA}$. Photoelectron peaks were calibrated relative to the $\mathrm{C} 1 \mathrm{~s}$ carbon line with a bond energy of $285 \mathrm{eV}$.

LB films transferred onto mica were also characterized by Atomic Force Microscopy (AFM). AFM is a technique based on the detection of weak forces existing between a tip and an object (the surface sample) which is scanned along the tip with a piezo scanner (maximum XYZ scan range of $130 \mu \mathrm{m} \times 130$ $\mu \mathrm{m} \times 12 \mu \mathrm{m})$. The tip is attached on a cantilever, and the tip sample forces are measured directly by the deflection of the cantilever on which a laser spot is reflected into an array of photodiodes. This technique can generate information concerning not only the topographical changes but also about the mechanical properties of the sample at the nanometer level (such as adhesion, viscoelasticity, or chemical composition) thanks to friction and phase images. ${ }^{45,46}$

Two AFM setups were used in this work, a MultiMode NanoScope III apparatus (AFM imaging), and a Bioscope II, mounted on an Olympus inverted optical microscope and operating with the NanoScope V controller (Veeco Bruker, Santa Barbara, CA). The AFM characterization (imaging) was performed under ambient air in tapping (dynamic) mode and scratching experiments were achieved in the contact mode. For the dynamic experiments, a commercial silicon tip cantilever was used (PPP NCL, NANOSENSORS), with a specified stiffness of about $40 \mathrm{~N} \cdot \mathrm{m}^{-1}$ and a measured resonance frequency of $307 \mathrm{kHz}$, with scan rates between 0.1 and $1 \mathrm{~Hz}$ (according to the scan size).

For each experiment, several images were recorded at the same time: trace and retrace height images (topography), error signal (amplitude images for the tapping mode, or deflection images for the contact mode), and mechanical properties (phase images for the tapping mode, friction images for the contact mode). According to the expected information, we want to highlight that we will show one or few of these images. For clarity, only flattened images $(512 \times 512$ pixels $)$ are shown.

\section{RESULTS AND DISCUSSION}

Figure 2 shows the $\pi$-A compression isotherms of non substituted and substituted phtalocyaninates, $\mathrm{CePc}_{2}$ and $\mathrm{Ce}\left[(15 \mathrm{C} 5)_{4} \mathrm{Pc}\right]_{2}$, respectively, and proposed model of molec ular orientation and aggregate structures that are formed in the monolayer at different surface pressure values. As shown in this figure, the substitution induces strong changes in the isotherm, with a shift of the isotherm to higher mean molecular areas and a change in the slope of the isotherm. Previous quantum chemical calculations gave information on the dimensions of these complexes, with disc area being around $500 \AA^{2}{ }^{36}$ The comparison of mean molecular areas combined with these calculations enable to propose an orientation of molecules at different stages of the compression. At low surface pressure, molecules are likely lying at the air-water interface. The compression first induces a regular increase of the surface

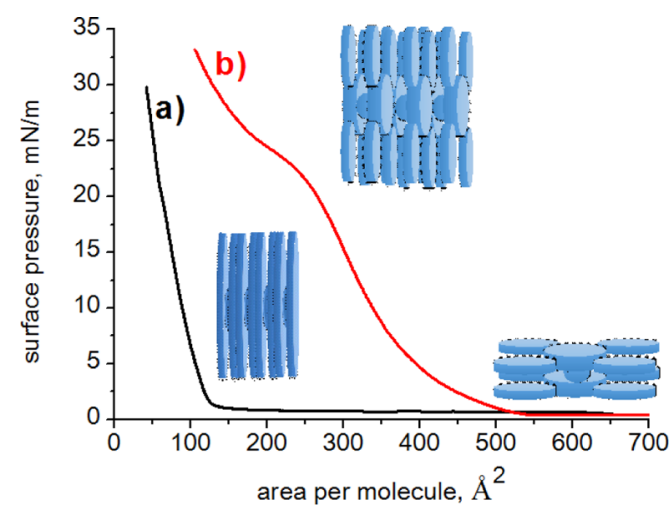

Figure 2. Compression isotherms of (a) $\mathrm{CePc}_{2}$ and (b) Ce $\left[(15 \mathrm{C} 5)_{4} \mathrm{Pc}\right]_{2}$ (ultrapure water used as subphase), $T=20 \pm 1{ }^{\circ} \mathrm{C}$, compression at $0.2 \mathrm{~mm} / \mathrm{s}$. Models of proposed molecular orientation and aggregate structures are presented on insets.

pressure until a plateau at surface pressures in the $22-27 \mathrm{mN}$. $\mathrm{m}^{-1}$ range. Since a regular increase of the tilt angle corresponding to a regular straightening of molecules is not likely for steric reasons, we can suppose that only some molecules switch to an upright position, while others are lying at the interface in this first part of the isotherm. At the end of the plateau, mean molecular areas around $170-180 \AA^{2}$ suggest that the planes of discotic molecules are all oriented perpendicularly to the air-water interface. This probably leads to the formation of stacks whose axes are parallel to the subphase surface. The fact that compression isotherms of nonsubstituted and crown substituted complex (Figure 2) converge at high surface pressure values is in agreement with this hypothesis, since their mean molecular areas are supposed to be in the same range in the upright orientation. It suggests also that both complexes form extensive stacking aggregates under such conditions.

In order to confirm the proposed monolayer architecture, these monolayers were transferred on mica at 20 and $35 \mathrm{mN}$. $\mathrm{m}^{-1}$ (i.e., below and above the change of slope on the isotherm) for investigation with AFM. Images obtained in tapping mode are shown in Figure 3. Figure 3a,b shows AFM images obtained from each LB film surface with the AFM tapping mode. The main information provided by these height images is the sample topography and more precisely the corrugation of the films (light areas being higher than the dark ones). As shown in Figure 3, at both surface pressures, images are heterogeneous, showing grid patterns in LB films and their density increases with the surface pressure. Height profiles, which are extracted from height cross sections in the $(X, Y)$ plane done on the corresponding height images, are more appropriate to get more qualitative and quantitative informa tion about LB film morphology both at a local level and over a wide scanned area. Figure $3 \mathrm{c}$,d shows typical height profile obtained in different areas of the LB films. One can suggest that the dark areas correspond to defects in a relatively uniform LB film. The height difference between these parts of the film, determined from the height profile (Figure 3), is in close agreement with the above mentioned highest dimension of a complex molecule. The thickness of the LB films is confirmed by AFM imaging after the scratching of an area with the tip: this thickness is obtained by the difference of height between the intact part of the LB film and the scratched one as indicated in Figure 4 . The estimated film thickness is about $1.8-2 \mathrm{~nm}$. This 
a
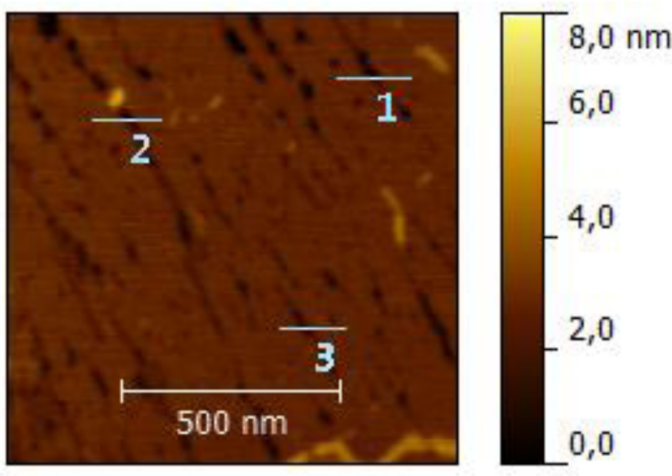

C

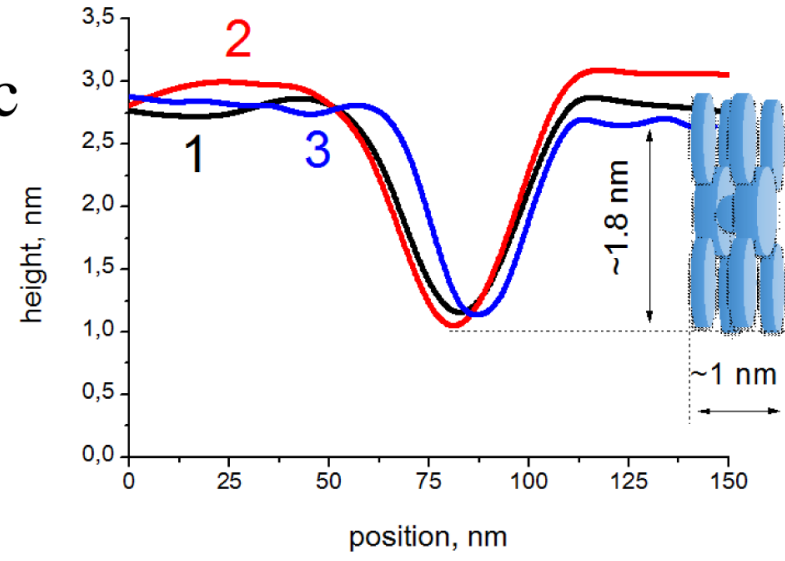

$\mathrm{b}$
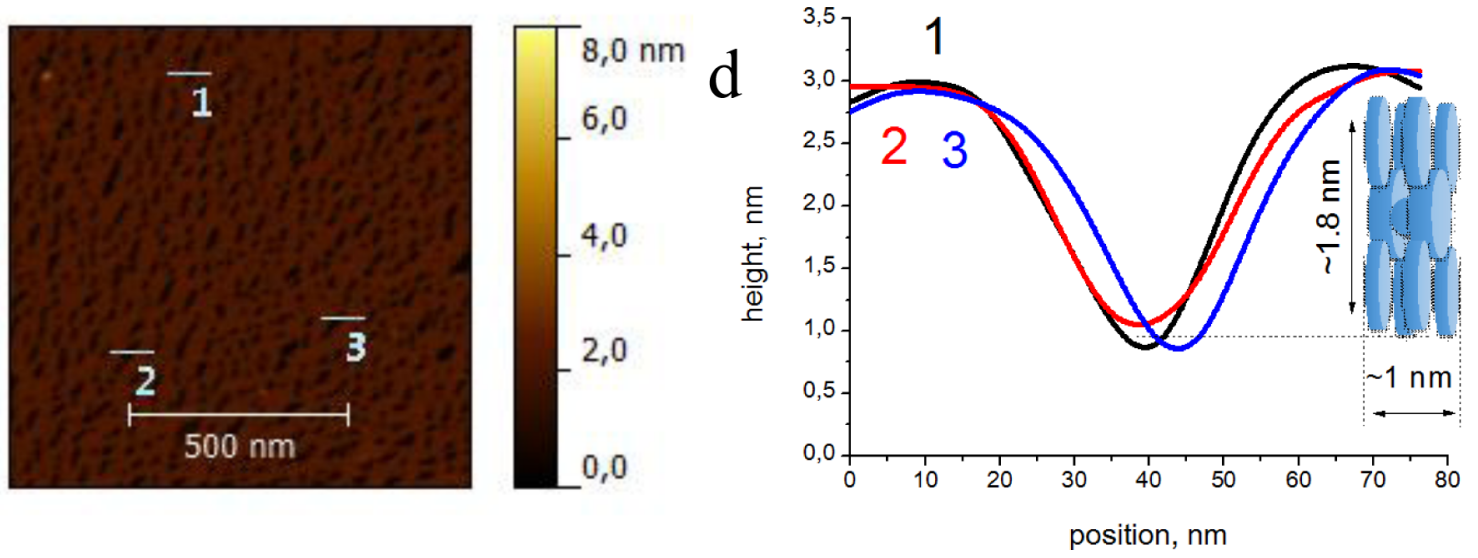

Figure 3. Height AFM images obtained in tapping mode of LB films of Ce[(15C5) $\left.)_{4} \mathrm{Pc}\right]_{2}$ transferred at (a) 20 and (b) $35 \mathrm{mN} \cdot \mathrm{m}^{-1}$ and $(\mathrm{c}, \mathrm{d})$ corresponding height profiles.
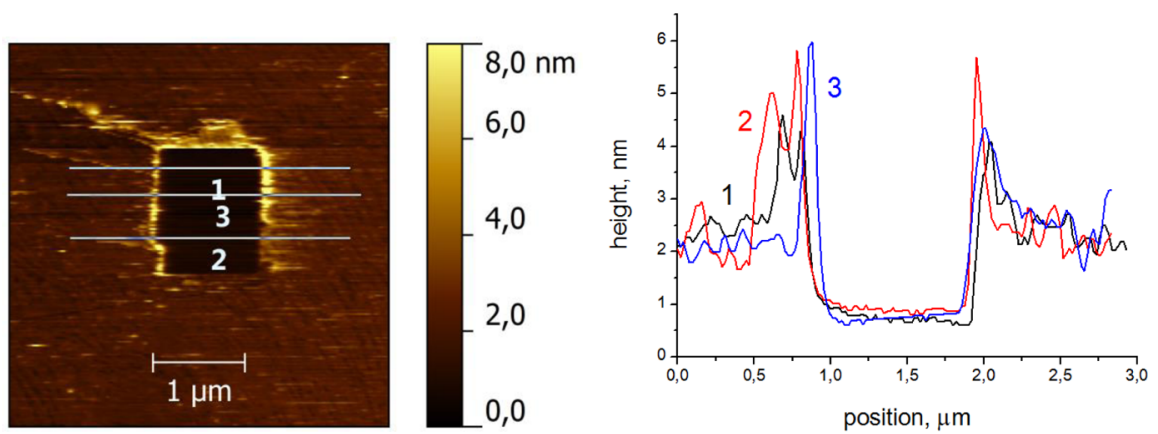

Figure 4. Height AFM image and section diagram of the $\mathrm{Ce}\left[(15 \mathrm{C} 5)_{4} \mathrm{Pc}\right]_{2} \mathrm{LBF}$ on mica substrate obtained in contact mode after a scratching experiment. Estimated film thickness is deduced after data processing of trace-retrace height profiles. The excessive height at the edge of the scratched area corresponds to a local accumulation of molecules pushed by the tip during the scratching experiment.

thickness value can correspond to either face on bilayer film (two molecule stacks with axes perpendicular to the substrate surface) or film consisting of discotic molecules organized in columnar stacks, their axes being parallel to the substrate surface. But values of mean molecular area, at which the films were transferred, indicate the impossibility of face on bilayer formation. Thus, AFM data together with monolayer compression isotherms allow us to conclude that at surface pressure values above $20 \mathrm{mN} \cdot \mathrm{m}^{-1}$, studied monolayers on both liquid and solid substrates consist of extensive stacking aggregates with edge on molecular orientation.

In order to reveal the possibility of a redox isomerization in monolayers of $\mathrm{Ce}\left[(15 \mathrm{C} 5)_{4} \mathrm{Pc}\right]_{2}$ we recorded in situ UV-vis differential reflection-absorption spectra (DRAS) ${ }^{44}$ of these monolayers at the air-water interface. They were recorded 15$20 \mathrm{~min}$ after spreading to achieve a complete evaporation of solvent and the completion of the spreading process. DRAS of monolayers are shown in Figure 5 with the UV-vis spectrum of the complex solubilized in chloroform at a concentration of 1.6 $\times 10^{-5} \mathrm{M}$. This last one (Figure 5, curve 1 ) is characterized by the presence of two intense bands at 650 and $700 \mathrm{~nm}(Q$ bands) and a broad band centered at $500 \mathrm{~nm}$, that is typical for the bisphthalocyanine compounds. ${ }^{18,25,26,34,47,48}$ The band at $500 \mathrm{~nm}$ indicates the presence of an unpaired electron in the double decker crown phthalocyaninate. The ratio of intensities of bands at 650 and $700 \mathrm{~nm}$ is indicative of the valent state of the cerium atom: in the case of $\mathrm{Ce}^{4+}$ short wavelength part of the $Q$ band is prevalent, and in the case of $\mathrm{Ce}^{3+}$, this part 


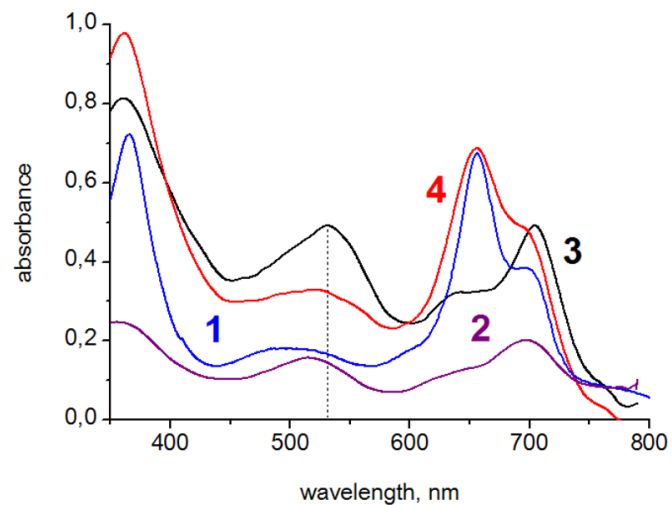

Figure 5. UV-vis spectra of (1) the $\mathrm{Ce}\left[(15 \mathrm{C} 5)_{4} \mathrm{Pc}\right]_{2}$ solution in chloroform, (2) monolayer just after spreading and at surface pressures of (3) 20 and (4) $35 \mathrm{mN} \cdot \mathrm{m}^{-1}$ after a few minutes. For illustrative purposes, the intensity of the solution spectrum is lowered to match that of monolayers at the wavelengths of $Q$ bands. Intensities of spectra 2-4 are multiplied by 20 for convenience of presentation on the figure.

remains only as a shoulder. As it was shown earlier, ${ }^{34}$ predominant valent state of cerium in this complex in chloroform solution was $\mathrm{Ce}^{4+}$.

DRAS of $\mathrm{Ce}\left[(15 \mathrm{C} 5)_{4} \mathrm{Pc}\right]_{2}$ monolayer just after spreading and solvent evaporation (Figure 5, curve 2) differs from the spectrum of the complex in solution. Intensities of $Q$ bands are redistributed in favor of the long wave one. In addition, an increase of intensity of the broad band at about $500 \mathrm{~nm}$ is observed, indicating the presence of an unpaired electron in the double decker crown phthalocyaninate.

The shape of monolayer DRAS becomes similar to the spectrum of the one electron oxidized complex $\left\{\left[(15 \mathrm{C} 5)_{4} \mathrm{Pc}^{2-}\right] \mathrm{Ce}^{4+}\left[(15 \mathrm{C} 5)_{4} \mathrm{Pc}^{-\bullet}\right]\right\}^{+34}$ At the same time, the observed set of bands could correspond also to an electro neutral complex with a trivalent metal center $\left\{\left[(15 \mathrm{C} 5)_{4} \mathrm{Pc}^{2-}\right]\right.$ $\left.\mathrm{Ce}^{3+}\left[(15 \mathrm{C} 5)_{4} \mathrm{Pc}^{-\bullet}\right]\right\}^{0}$ as the position and shape of $Q$ band is determined predominantly by electronic structure of phthalo cyanine anion itself but not metal. ${ }^{49}$ In other words, the observed spectral changes result from the transfer of one electron from the molecular orbital of the phthalocyanine ligand, but there are two possible pathways for this transition. The first one consists of the oxidation of the phthalocyanine ligand by some external oxidizer (cation radical formation, i.e., one electron transfer from ligand to oxidizer). The second one deals with the transfer of an electron from the phthalocyanine ligand to the metal center (IET, i.e., $\mathrm{Ce}^{4+} / \mathrm{Ce}^{3+}$ trans formation).

In order to establish the pathway of the electron transfer that causes these spectral changes, we performed similar inves tigations for a series of analogous $\operatorname{Ln}\left[(15 \mathrm{C} 5)_{4} \mathrm{Pc}\right]_{2}$ complexes of trivalent lanthanides $\left(\mathrm{Ln}=\mathrm{Pr}^{3+}, \mathrm{Tb}^{3+}, \mathrm{Yb}^{3+}, \mathrm{Lu}^{3+}\right)$ under the same experimental conditions (Figure 6). It was found that no analogous spectral changes occur upon spreading and compression of monolayers of these complexes, that is in conformity with the fact that these lanthanide ions can only exhibit a $3+$ oxidation state in these complexes. ${ }^{26,38}$ Spectra of monolayer of unsubstituted $\mathrm{CePc}_{2}$, in which $\mathrm{Ce}^{4+}$ state is much more stable than in crown substituted complex, ${ }^{7,15,34}$ also do not undergo such alterations upon deposition and compression and do not possess the band at about $500 \mathrm{~nm}$ (Figure 6, curve 1). At last, the positions of bands at about $500 \mathrm{~nm}$ in DRAS of trivalent lanthanide complexes at the air-water interface

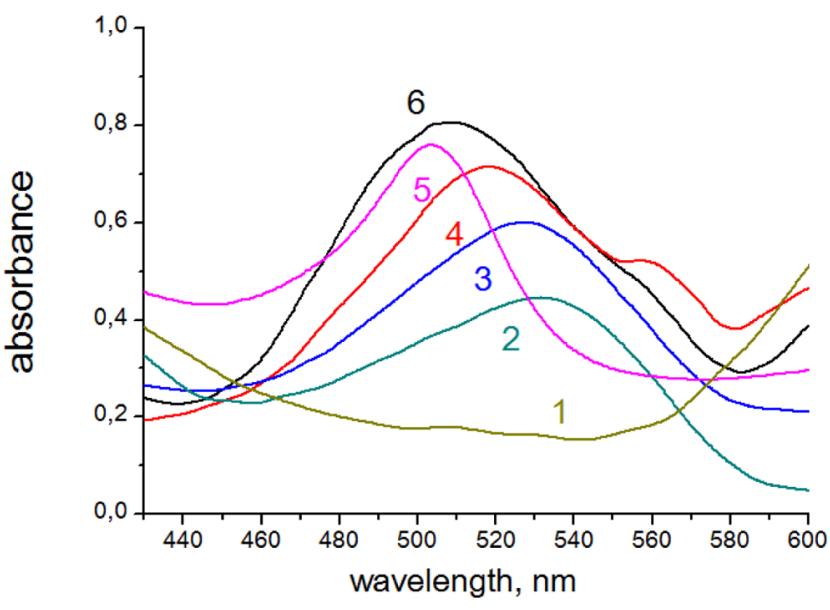

Figure 6. UV-vis spectra of monolayers of (1) $\mathrm{CePc}_{2}$, (2) $\mathrm{Ce}\left[(15 \mathrm{C} 5)_{4} \mathrm{Pc}\right]_{2}$, (3) $\operatorname{Pr}\left[(15 \mathrm{C} 5)_{4} \mathrm{Pc}\right]_{2}, \quad$ (4) $\mathrm{Tb}\left[(15 \mathrm{C} 5)_{4} \mathrm{Pc}\right]_{2}, \quad$ (5) $\mathrm{Yb}\left[(15 \mathrm{C} 5)_{4} \mathrm{Pc}\right]_{2}$, and $(6) \mathrm{Lu}\left[(15 \mathrm{C} 5)_{4} \mathrm{Pc}\right]_{2}$ at surface pressure about $5 \mathrm{mN} \cdot \mathrm{m}^{-1}$ (area of the $\pi$ radical anion band (ca. $500 \mathrm{~nm}$ )). Intensities of all spectra are multiplied by 20 for convenience of presentation on the figure.

recorded at $5 \mathrm{mN} \mathrm{m}^{-1}$ surface pressure (Figure 6, curves 26) are linearly correlated with corresponding ionic radii (Figure 7). As can be seen, the experimental value for the crown

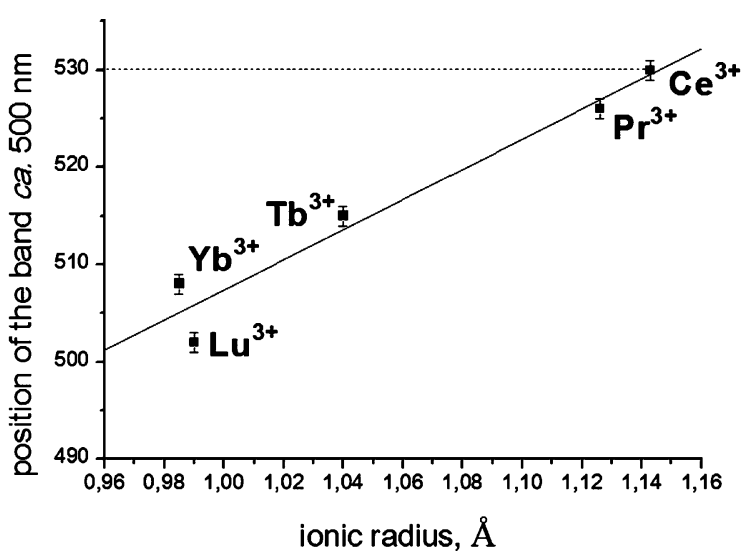

Figure 7. Correlation dependence between the ionic radii of the lanthanide metal centers and the position of the band at about $500 \mathrm{~nm}$ in spectra of the corresponding complex monolayers shown in Figure

substituted cerium complex monolayer corresponds to the radius of $\mathrm{Ce}^{3+}$ cation. This result confirms that the central metal ion of cerium double decker bis [tetra ( 15 crown 5) phthalo cyaninate] becomes trivalent upon deposition of the complex chloroform solution to the air-water interface and its further spreading over the surface as a result of an IET from the phthalocyanine macrocycle $\pi$ system to the cerium $4 f$ orbital.

A similar shift of dynamic equilibrium between redox isomers was observed for copper complexes with organic ligands in solvents of different polarities. ${ }^{4}$ In the case of the transition of complex discotic molecules from chloroform solution (3D system) to the air-water interface (2D one), not only the solvent characteristics change, but also the orientation of $\mathrm{Ce}\left[(15 \mathrm{C} 5)_{4} \mathrm{Pc}\right]_{2}$ molecules moving from a random orientation in solution to a more homogeneous one at the interface. This $3 \mathrm{D} \leftrightarrow 2 \mathrm{D}$ effect constitutes an additional contribution to the driving force of IET and participates in the shift of the 
environmental dependent equilibrium. Evidently, spreading of the solution of sandwich type crown phthalocyaninate on the water surface leads to a horizontal ("face on") orientation of discotic molecules, as shown by mean molecular areas in the isotherm. The induced hydration of crown ether substituents of one phthalocyanine deck, whichever interacts with polar subphase, violates the symmetry of the complex electronic system and enhances the mobility of $\pi$ electrons and the electron donating properties of unsolvated moieties oriented toward air. Eventually it makes the IET to the metal center easier. Such redox isomerization can partially compensate the influence of asymmetrical hydration, and thereby dynamic equilibrium in the system shifts toward the trivalent metal complex formation.

The subsequent compression of monolayer up to $22 \mathrm{mN}$. $\mathrm{m}^{-1}$ results only in a simultaneous increase of intensities of all bands in DRAS. The most interesting results, however, were found after compression of monolayer up to a surface pressure of $25-30 \mathrm{mN} \cdot \mathrm{m}^{-1}$. Achievement of these relatively high $\pi$ values leads to unexpected transformation of the complex reflection-absorption spectrum, if the monolayer is kept a few minutes at these pressures. In this case, the spectrum becomes similar to the spectrum of the complex in chloroform solution with $\mathrm{Ce}^{4+}$ (Figure 5). It should be noted that $\mathrm{Ce}^{3+} \leftrightarrow \mathrm{Ce}^{4+}$ transformation occurring upon monolayer compression is reversible: when surface pressure decreases upon monolayer expansion, DRAS gradually reverts to the one observed before compression (Figure 5, curve 2).

The reversibility of spectral changes in the absence of reducing agents evidences, once again, that the transformation observed upon spreading of complex solution onto air-water interface is not determined by its oxidation. Such types of transformations (oxidation/reduction) could not be reversible under the given experimental conditions. This experimental observation strengthens the hypothesis of an IET process versus oxidation. Obtained results allow to conclude that the spreading of the complex solution at the air-water interface is accompanied by an IET from the $\pi$ system of the phthalocyanine macrocycle to $4 f$ orbital of cerium ion according to the following scheme $\left[\left((15 \mathrm{C} 5)_{4} \mathrm{Pc}^{2-}\right) \mathrm{Ce}^{4+}\left((15 \mathrm{C} 5)_{4} \mathrm{Pc}^{2-}\right)\right]$ $\rightarrow\left[\left((15 \mathrm{C} 5)_{4} \mathrm{Pc}^{2-}\right) \mathrm{Ce}^{3+}\left((15 \mathrm{C} 5)_{4} \mathrm{Pc}^{-\bullet}\right)\right]$. Compression of the monolayer to high values of surface pressure induces the reverse IET. This second IET governed by surface pressure is reversible and can be described as $\left[\left((15 \mathrm{C} 5)_{4} \mathrm{Pc}^{2-}\right)\right.$ $\left.\mathrm{Ce}^{3+}\left((15 \mathrm{C} 5)_{4} \mathrm{Pc}^{-\bullet}\right)\right] \leftrightarrow\left[\left((15 \mathrm{C} 5)_{4} \mathrm{Pc}^{2-}\right) \mathrm{Ce}^{4+}\left((15 \mathrm{C} 5)_{4} \mathrm{Pc}^{2-}\right)\right]$ equilibrium, which can be considered as an orientation induced redox isomerism.

What is the thermodynamic foundation of this process? During the compression, discotic molecules straighten, adopting a vertical ("edge on") orientation and forming stacks whose axes are parallel to the subphase surface. One can assume that a further compression decreases the activation energy of the electronic transition from the cerium $4 f$ orbital to the conjugated electronic system of ligands in stacks. It is known from $X$ ray photoelectron measurements ${ }^{50,51}$ that the electron binding energy for the $4 f$ orbital of Ce atom is very low $(0.1 \mathrm{eV})$, as it is screened from the nucleus to a big extent by the remaining electrons of this electron rich atom. This anomalously low value is the reason for the facilitation of electron transitions in cerium double decker complex. Taking this effect into account, we suppose that a high lateral pressure of about $25-30 \mathrm{mN} \cdot \mathrm{m}^{-1}$ results in a high density of stack packing and thereby facilitates the change of valent state of the metal center $\mathrm{Ce}^{3+} \rightarrow \mathrm{Ce}^{4+}$, since this transition leads to the conjugation of electronic systems of the molecules in stacks due to electron delocalization. Moreover, the switching of the central ion oxidation state from $3+$ to $4+$ is accompanied by a decrease of the distance between decks. Such a downsizing under $2 \mathrm{D}$ compression is thermodynamically favorable in terms of attaining the minimum of mean molecular area.

The 2D system energy change upon the change of molecular size can be estimated as $\pi \Delta S$, where $\Delta S=S_{3+}-S_{4+}$ with $S_{3+}$ and $S_{4+}$ being the areas of $1 \mathrm{~mol}$ of $\left[\left((15 \mathrm{C} 5)_{4} \mathrm{Pc}^{2-}\right)\right.$ $\left.\mathrm{Ce}^{3+}\left((15 \mathrm{C} 5)_{4} \mathrm{Pc}^{-\bullet}\right)\right]$ and $\left[\left((15 \mathrm{C} 5)_{4} \mathrm{Pc}^{2-}\right) \mathrm{Ce}^{4+}\left((15 \mathrm{C} 5)_{4} \mathrm{Pc}^{2-}\right)\right]$ in close packed monolayers, respectively. Such a simple estimation shows that at $\pi=35 \mathrm{mN} \cdot \mathrm{m}^{-1} \pi \Delta S \approx 6 \mathrm{~kJ} \mathrm{~mol}^{-1}$ (details of the calculation are given in Supporting Information). This value is very close to the value of energy required to transfer the electron from the Ce $4 f$ orbital to the Fermi level, that is, the above mentioned electron binding energy $(0.1 \mathrm{eV}$, corresponds to $\left.9.6 \mathrm{~kJ} \mathrm{~mol}^{-1}\right) .{ }^{50,51}$ Nearly equal values of these physical quantities indicate that IET in $2 \mathrm{D}$ systems under consideration can be caused by the monolayer compression at a high surface pressure. These results prove that the reversible spectral changes observed for $\mathrm{Ce}\left[(15 \mathrm{C} 5)_{4} \mathrm{Pc}\right]_{2}$ complex upon compression originate from the switching of the cerium redox state. In other words, we are dealing here with a two dimensional phase transition controlled by surface pressure and demonstrate the first example of an orientation induced redox isomerism phenomenon in planar supramolecular systems. It is also one of the first examples of a genuine redox isomerism in a rare earth metal complex in monolayer. $8,9,52,53$

At last, the redox behavior of cerium double decker complex in Langmuir monolayers is supposed to impact the properties of LB films on the solid substrate. The comparison of UV-vis spectra of $\mathrm{Ce}\left[(15 \mathrm{C} 5)_{4} \mathrm{Pc}\right]_{2} \mathrm{LB}$ films transferred onto quartz plates at 20 and $35 \mathrm{mN} \cdot \mathrm{m}^{-1}$ with spectra of corresponding monolayers reveals that the transfer of the monolayer onto the solid substrate does not lead to any significant spectral changes (Figure S9). The difference in valent states of the metal center of the double decker cerium bis [tetra ( 15 crown 5$)$ phthalo cyaninate] in LB films transferred at different surface pressures is also proved by the $\mathrm{X}$ ray photoelectron spectroscopy (XPS) technique.

The XPS spectrum obtained for $\operatorname{Pr}\left[(15 \mathrm{C} 5)_{4} \mathrm{Pc}\right]_{2} \mathrm{LB}$ film, transferred at $35 \mathrm{mN} \cdot \mathrm{m}^{-1}$ (Figure 8) indicates that the amount of $\operatorname{Pr}^{3+}$ cations in the film is in stoichiometric proportion with

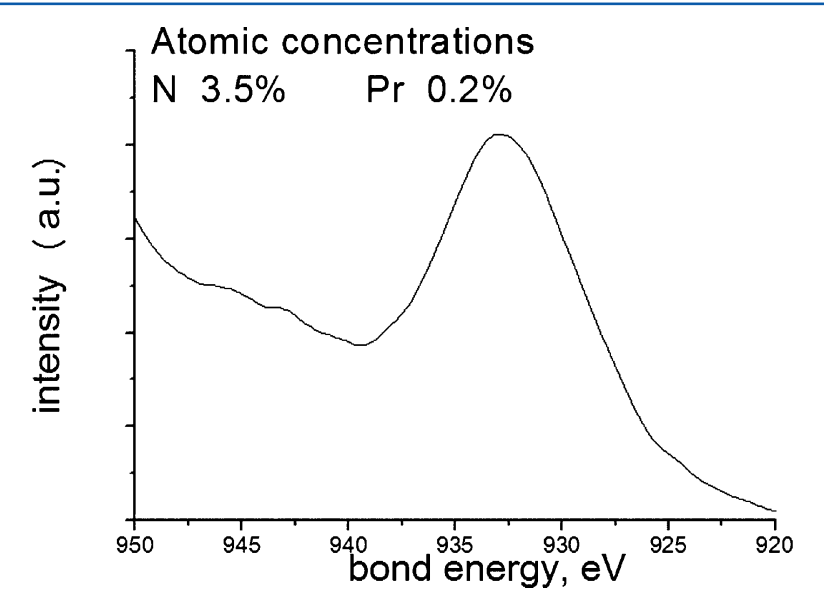

Figure 8. X ray photoelectron spectrum of $\mathrm{LB}$ film of $\operatorname{Pr}\left[(15 \mathrm{C} 5)_{4} \mathrm{Pc}\right]_{2}$ transferred at $35 \mathrm{mN} \cdot \mathrm{m}^{-1}$. 
respect to $\mathrm{N}$ atoms, thus confirming the reliability of the XPS technique for determination of lanthanide valent states in ultrathin films.

XPS spectrum of LB films of $\mathrm{Ce}\left[(15 \mathrm{C} 5)_{4} \mathrm{Pc}\right]_{2}$ transferred at $20 \mathrm{mN} \cdot \mathrm{m}^{-1}$ (Figure 9a) shows the presence of two bands at

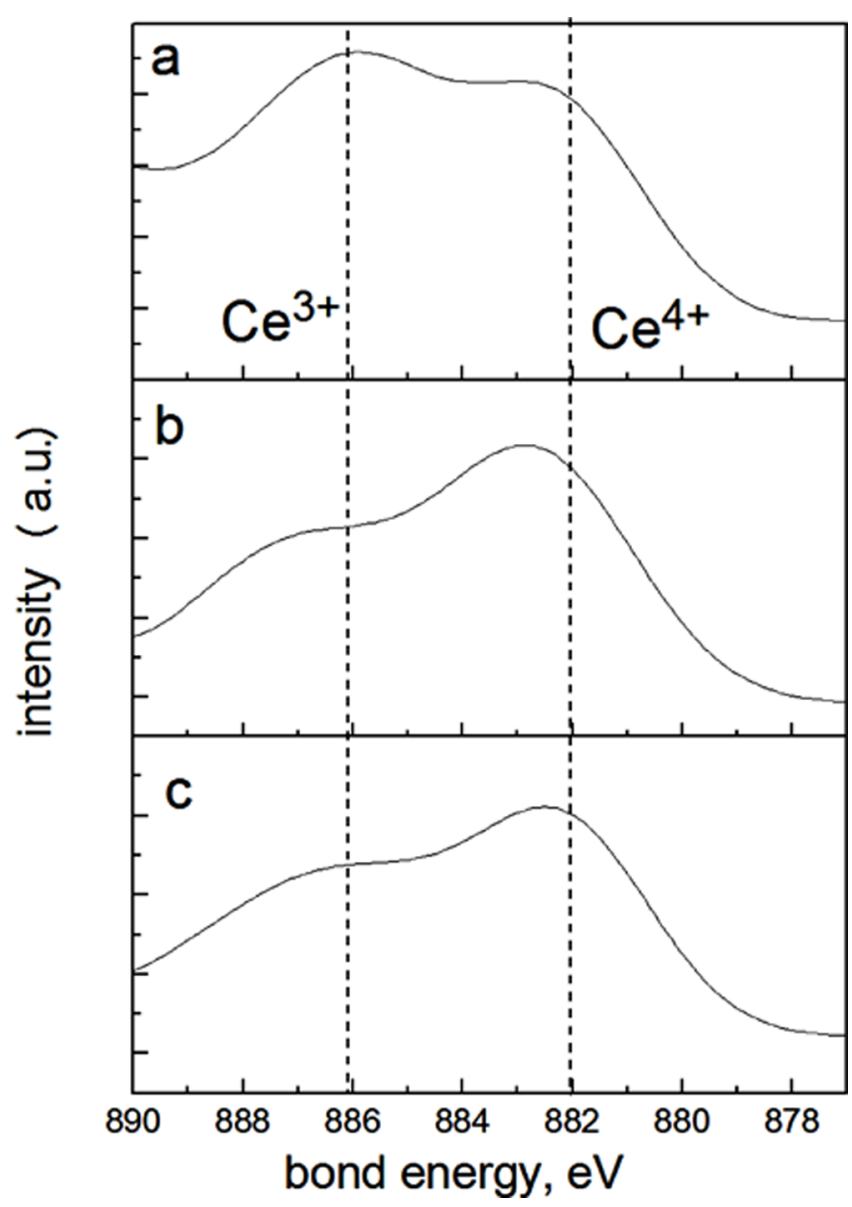

Figure 9. $\mathrm{X}$ ray photoelectron spectra of $\mathrm{LB}$ films of $\mathrm{Ce}\left[(15 \mathrm{C} 5)_{4} \mathrm{Pc}\right]_{2}$ transferred at (a) 20 and (b) $35 \mathrm{mN} \cdot \mathrm{m}^{-1}$, and (c) LB films of $\mathrm{CePc}_{2}$ obtained at $20 \mathrm{mN} \cdot \mathrm{m}^{-1}$.

882.2 and $886.0 \mathrm{eV}$ assigned to $\mathrm{Ce}^{4+}$ and $\mathrm{Ce}^{3+}$, respec tively. ${ }^{54-56}$ Both oxidation states are thus present in the films, even if the molecules with a trivalent metal center are predominant. On the contrary, molecules with a tetravalent metal center are predominant in LB films transferred at $35 \mathrm{mN}$. $\mathrm{m}^{-1}$ (Figure $9 \mathrm{~b}$ ) and in LB films produced from unsubstituted $\mathrm{Ce}^{4+}\left[\mathrm{Pc}^{2-}\right]_{2}$ formed at $20 \mathrm{mN} \cdot \mathrm{m}^{-1}$ for which no IET was found (Figure 9c).

These results allowed us to conclude that the valent states of the metal center in monolayers and corresponding LB films transferred at different values of surface pressure are identical. Therefore, the transfer of a Langmuir monolayer onto a solid substrate by the LB technique does not alter the electronic and structural states of the cerium complex: the redox isomerization in the monolayer allows one to tune LB films characteristics.

\section{CONCLUSION}

In conclusion, we present here evidence of an unprecedented reversible orientation induced IET associated with a redox isomerism of discotic molecules of cerium bis phthalocyanine in Langmuir monolayers. We were able to transfer these monolayers onto solid substrates forming LB films of two different redox isomers of the studied complex. These ultrathin films consist of extensive supramolecular aggregates organized in fibrous planar bundles of columnar stacks, and their structure and redox isomeric state of $\mathrm{Ce}\left[(15 \mathrm{C} 5)_{4} \mathrm{Pc}\right]_{2}$ can be tuned by varying the surface pressure during the monolayer transfer. The redox isomerism was also found upon spreading of $\mathrm{Ce}$ $\left[(15 \mathrm{C} 5)_{4} \mathrm{Pc}\right]_{2}$ dissolved in chloroform over the air-water interface at which $\mathrm{Ce}^{4+}$ cation in the solution transforms into $\mathrm{Ce}^{3+}$ in the monolayer $(3 \mathrm{D} \rightarrow 2 \mathrm{D}$ IET). Mechanisms of both IETs were proposed and supported by several techniques. Such systems could open the way to the development of new nanoscale multibit information storage devices.

\section{AUTHOR INFORMATION}

\section{Corresponding Author}

*Tel.: +7(495)9554408. Fax: +7(495)9525308. E mail: sofselector@hotmail.com.

\section{Notes}

The authors declare no competing financial interest.

\section{ACKNOWLEDGMENTS}

This work was financially supported by Russian Foundation for Basic Research Grant Nos. 130312473 ofi m2, 130300677 a, and $140331817 \mathrm{~mol} \mathrm{a}$, and the program of the Russian Academy of Sciences Presidium P8(5) and a program of cooperation between the Russian Academy of Sciences and the French Centre National de la Recherche Scientifique (CNRS).

\section{REFERENCES}

(1) Creutz, C.; Taube, H. Direct Approach to Measuring the Franck Condon Barrier to Electron Transfer between Metal Ions. J. Am. Chem. Soc. 1969, 91, 3988-3989.

(2) Gütlich, P.; Garcia, Y.; Woike, T. Photoswitchable Coordination Compounds. Coord. Chem. Rev. 2001, 221, 839-879.

(3) Evangelio, E.; Bonnet, M. L.; Cabañas, M.; Nakano, M.; Sutter, J. P.; Dei, A.; Robert, V.; Ruiz Molina, D. Coexistence of Two Thermally Induced Intramolecular Electron Transfer Processes in a Series of Metal Complexes $[\mathrm{M}($ Cat N BQ $)($ Cat N SQ $)] /\left[\mathrm{M}(\text { Cat N BQ })_{2}\right](\mathrm{M}$ $=\mathrm{Co}, \mathrm{Fe}$, and Ni) Bearing Non Innocent Catechol Based Ligands: A Combined Experimental and Theoretical. Chemistry 2010, 16, 66666677.

(4) Abakumov, G. A.; Cherkasov, V. K.; Nevodchikov, V. I.; Kuropatov, V. A.; Yee, G. T.; Pierpont, C. G. Magnetic Properties and Redox Isomerism for 4,4' Bis(semiquinone) Complexes of Copper. Inorg. Chem. 2001, 40, 2434-2436.

(5) Lehtivuori, H.; Kumpulainen, T.; Hietala, M.; Efimov, A.; Lemmetyinen, H.; Kira, A.; Imahori, H.; Tkachenko, N. V. Photodynamics of Charge Separation and Recombination in Solid Alternating Films of Phthalocyanine or Phthalocyanine-Fullerene Dyad and Perylene Dicarboximide. J. Phys. Chem. C 2009, 113, 19841992.

(6) Pierpont, C. G. Studies on Charge Distribution and Valence Tautomerism in Transition Metal Complexes of Catecholate and Semiquinonate Ligands. Coord. Chem. Rev. 2001, 216-217, 99-125.

(7) D'Souza, F.; Maligaspe, E.; Sandanayaka, A. S. D.; Subbaiyan, N. K.; Karr, P. A.; Hasobe, T.; Ito, O. Photochemical Charge Separation in Supramolecular Phthalocyanine Multifullerene Conjugates As sembled by Crown Ether Alkyl Ammonium Cation Interactions. J. Phys. Chem. A 2010, 114, 10951-10959.

(8) Fedushkin, I. L.; Maslova, O. V; Morozov, A. G.; Dechert, S.; Demeshko, S.; Meyer, F. Genuine Redox Isomerism in a Rare Earth Metal Complex. Angew. Chem., Int. Ed. 2012, 51, 10584-10587. 
(9) Fedushkin, I. L.; Maslova, O. V.; Lukoyanov, A. N.; Fukin, G. K. Anionic and Neutral Bis(diimine)lanthanide Complexes. C. R. Chim. 2010, 13, 584-592.

(10) Poneti, G.; Mannini, M.; Sorace, L.; Sainctavit, P.; Arrio, M. A.; Otero, E.; Cezar, J. C.; Dei, A. Soft X ray Induced Redox Isomerism in a Cobalt Dioxolene Complex. Angew. Chem., Int. Ed. 2010, 49, 19541957.

(11) Dei, A.; Sorace, L. Cobalt Dioxolene Redox Isomers: Potential Spintronic Devices. Appl. Magn. Reson. 2010, 38, 139-153.

(12) Zhang, X. F.; Wang, J. Morpholine Phthalocyanine (Donor Acceptor) Construct: Photoinduced Intramolecular Electron Transfer and Triplet Formation from Its Charge Separation State. J. Phys. Chem. A 2011, 115, 8597-8603.

(13) Trifonov, A. A.; Borovkov, I. A.; Fedorova, E. A.; Fukin, G. K.; Larionova, J.; Druzhkov, N. O.; Cherkasov, V. K. Ytterbocenes as One and Two Electron Reductants in Their Reactions with Diazadienes: YbIII Mixed Ligand Bent Sandwich Complexes Containing a Dianion of Diazabutadiene. Chemistry 2007, 13, 4981-4987.

(14) Kobayashi, N. Dimers, Trimers, and Oligomers of Phthalocya nines and Related Compounds. Coord. Chem. Rev. 2002, 227, 129152.

(15) Bian, Y.; Jiang, J.; Tao, Y.; Choi, M. T. M.; Li, R.; Ng, A. C. H.; Zhu, P.; Pan, N.; Sun, X.; Arnold, D. P.; et al. Tuning the Valence of the Cerium Center in $(\mathrm{Na})$ phthalocyaninato and Porphyrinato Cerium Double Deckers by Changing the Nature of the Tetrapyrrole Ligands. J. Am. Chem. Soc. 2003, 125, 12257-12267.

(16) Gorbunova, Y.; Martynov, A.; Tsivadze, A. Crown Substituted Phthalocyanines: From Synthesis Towards Materials. In Handbook of Porphyrin Science; Kadish, K., Smith, K., Guilard, R., Eds.; World Scientific Publishing: Singapore, 2012; pp 271-388.

(17) Grishina, A. D.; Gorbunova, Y. G.; Zolotarevsky, V. I.; Pereshivko, L. Y.; Enakieva, Y. Y.; Krivenko, T. V.; Savelyev, V.; Vannikov, A. V.; Tsivadze, A. Y. Solvent Induced Supramolecular Assemblies of Crown Substituted Ruthenium Phthalocyaninate: Morphology of Assemblies and Non Linear Optical Properties. J. Porphyrins Phthalocyanines 2009, 13, 92-98.

(18) Gorbunova, Y. G.; Enakieva, Y. Y.; Sakharov, S. G.; Tsivadze, A. Y. Synthesis and Spectral Properties of Ruthenium(II) Complexes with Tetra 15 crown 5 phthalocyanine and N Donor Ligands. J. Porphyrins Phthalocyanines 2003, 07, 795-800.

(19) Vannikov, A. V.; Grishina, A. D.; Gorbunova, Y. G.; Krivenko, T. V.; Laryushkin, A. S.; Lapkina, L. A.; Savelyev, V. V.; Tsivadze, A. Y. Photoelectric, Nonlinear Optical, and Photorefractive Properties of Composites Based on Poly ( $N$ vinylcarbazole) and Gallium Phthalo cyaninate. Polym. Sci., Ser. A 2011, 53, 1069-1075.

(20) Vannikov, A. V.; Gorbunova, Y. G.; Grishina, A. D.; Tsivadze, A. Y. Photoelectric, Nonlinear Optical, and Photorefractive Properties of Polymer Composites Based on Supramolecular Ensembles of $\mathrm{Ru}$ (II) and $\mathrm{Ga}(\mathrm{III})$ Complexes with Tetra 15 crown 5 phthalocyanine. Prot. Met. Phys. Chem. Surfaces 2013, 49, 57-65.

(21) Gorbunova, Y. G.; Lapkina, L. A.; Tsivadze, A. Y. Supra molecular Systems Constructed from Crownphthalocyaninates. J. Coord. Chem. 2003, 56, 1223-1232.

(22) Enakieva, Y. Y.; Gorbunova, Y. G.; Nefedov, S. E.; Tsivadze, A. $\mathrm{Y}$. Synthesis and Structure of the $\left(\mathrm{R}_{4} \mathrm{Pc}\right) \mathrm{Ru}(\mathrm{TED})_{2}$ Complex, where $\mathrm{R}_{4} \mathrm{Pc}^{2-}$ is the Tetra 15 crown 5 phthalocyaninate Dianion and TED Is Triethylenediamine. Mendeleev Commun. 2004, 14, 193-194.

(23) Martynov, A. G.; Zubareva, O. V.; Gorbunova, Y. G.; Sakharov, S. G.; Nefedov, S. E.; Dolgushin, F. M.; Tsivadze, A. Y. Diphthalocyaninatolanthanum as a New Phthalocyaninato Dianion Donor for the Synthesis of Heteroleptic Triple Decker Rare Earth Element Crown Phthalocyaninato Complexes. Eur. J. Inorg. Chem. 2007, 4800-4807.

(24) Martynov, A. G.; Zubareva, O. V.; Gorbunova, Y. G.; Sakharov, S. G.; Tsivadze, A. Y. Synthesis, Spectral Properties, and Supra molecular Dimerisation of Heteroleptic Triple Decker Phthalocyani nato Complexes with One Outer Crown Substituted Ligand. Inorg. Chim. Acta 2009, 362, 11-18.
(25) Jiang, J.; Ng, D. K. P. A Decade Journey in the Chemistry of Sandwich Type Tetrapyrrolato-Rare Earth Complexes. Acc. Chem. Res. 2009, 42, 79-88.

(26) Gorbunova, Y. G.; Lapkina, L. A.; Martynov, A. G.; Biryukova, I. V.; Tsivadze, A. Y. Lanthanide Crownphthalocyaninates: Synthesis, Structure, and Peculiarities of Formation. Russ. J. Coord. Chem. 2004, 30, 245-251.

(27) Weiss, R.; Fischer, J. The Porphyrin Handbook. In The Porphyrin Handbook; Kadish, K., Smith, R., Guilard, R., Eds.; Academic Press: San Diego, 2000.

(28) Pushkarev, V. E.; Tomilova, L. G.; Tomilov, Y. V Synthetic Approaches to Lanthanide Complexes with Tetrapyrrole Type Ligands. Russ. Chem. Rev. 2008, 77, 875-907.

(29) Jiang, J.; Bao, M.; Rintoul, L.; Arnold, D. P. Vibrational Spectroscopy of Phthalocyanine and Naphthalocyanine in Sandwich Type (Na)phthalocyaninato and Porphyrinato Rare Earth Complexes. Coord. Chem. Rev. 2006, 250, 424-448.

(30) Liu, J.; Lo, P.; Ng, D. K. P.; Jiang, J.; Bekaroglu, O. Functional Phthalocyanine Molecular Materials; Jiang, J., Ed.; Springer: Berlin; Heidelberg, 2010; Vol. 135.

(31) Haraguchi, N.; Okaue, Y.; Isobe, T.; Matsuda, Y. Stabilization of Tetravalent Cerium upon Coordination of Unsaturated Heteropoly tungstate Anions. Inorg. Chem. 1994, 33, 1015-1020.

(32) Takahashi, Y.; Shimizu, H.; Usui, A.; Kagi, H.; Nomura, M. Direct Observation of Tetravalent Cerium in Ferromanganese Nodules and Crusts by $\mathrm{X}$ ray Absorption Near Edge Structure (XANES). Geochim. Cosmochim. Acta 2000, 64, 2929-2935.

(33) Arnold, P.; Casely, I.; Zlatogorsky, S.; Wilson, C. Organo metallic Cerium Complexes from Tetravalent Coordination Com plexes. Helv. Chim. Acta 2009, 92, 2291-2303.

(34) Birin, K. P.; Gorbunova, Y. G.; Tsivadze, A. Y. The Features of Cerium Coordination Chemistry in the Complexes with Tetra 15 crown 5 phthalocyanine. J. Porphyrins Phthalocyanines 2006, 10, 931936.

(35) Jiang, J.; Liu, W.; Poon, K. W.; Du, D.; Arnold, D. P.; Ng, D. K. P. Synthesis, Spectroscopic, and Electrochemical Properties of Rare Earth Double Deckers with Tetra(tert butyl) 2,3 naphthalocyaninato Ligands. Eur. J. Inorg. Chem. 2000, 2000, 205-209.

(36) Selector, S. L.; Arslanov, V. V.; Gorbunova, Y. G.; Raitman, O. A.; Sheinina, L. S.; Birin, K. P.; Tsivadze, A. Y. Redox Controlled Multistability of Double Decker Cerium Tetra (15 crown 5) phthalo cyaninate Ultrathin Films. J. Porphyrins Phthalocyanines 2008, 12, $1154-1162$.

(37) Selector, S. L.; Shokurov, A. V; Arslanov, V. V; Gorbunova, Y. G.; Raitman, O. A.; Isakova, A. A.; Birin, K. P.; Tsivadze, A. Y. Electrochemically Controlled Multistability of Ultrathin Films of Double Decker Cerium Phthalocyaninates. Russ. J. Electrochem. 2012, $48,218-233$.

(38) Selektor, S. L.; Shokurov, A. V.; Raitman, O. A.; Sheinina, L. S.; Arslanov, V. V.; Birin, K. P.; Gorbunova, Y. G.; Tsivadze, A. Y. Orientation Induced Redox Transformations in Langmuir Monolayers of Double Decker Cerium Bis[tetra (15 crown 5) phthalocyaninate] and Multistability of Its Langmuir-Blodgett Films. Colloid J. 2012, 74, 334-345.

(39) Birin, K. P.; Gorbunova, Y. G.; Tsivadze, A. Y. Synthesis and Spectroscopic Study of Praseodymium(III) Complexes with Tetra 15 crown 5 phthalocyanine. Russ. J. Inorg. Chem. 2007, 52, 191-196.

(40) Nefedova, I. V.; Gorbunova, Y. G.; Sakharov, S. G.; Tsivadze, A. Y. Synthesis and Spectroscopic Study of Terbium(III) and Neodymium(III) Complexes with Tetra 15 crown 5 phthalocyanine. Russ. J. Inorg. Chem. 2005, 50, 165-173.

(41) Birin, K. P.; Gorbunova, Y. G.; Tsivadze, A. Y. Efficient Scrambling Free Synthesis of Heteroleptic Terbium Triple Decker (Porphyrinato)(crown Phthalocyaninates). Dalton Trans. 2012, 41, 9672-96. 
(42) Lapkina, L. A.; Gorbunova, Y. G.; Nefedov, S. E.; Tsivadze, A. Y. First Example of Structurally Characterized Double Decker Sandwich Rare Earth Metal Complex with Crown Substituted Phthalocyanine. Synthesis and Structure of $\operatorname{Bis}[\operatorname{tetra}(15$ crown 5)phthalocyaninato] ytterbium(III). Russ. Chem. Bull. 2003, 52, 1633-1636.

(43) Tolkacheva, O. E.; Tsivadze, A. Y.; Bitiev, S. G.; Gorbunova, Y. G.; Zhilov, V. I.; Minin, V. V. Template Synthesis of Lutecium Tetracrown Substituted Phthalocyanines in Fusions and Their Spectroscopic Study. Russ. J. Inorg. Chem. 1995, 40, 984-989.

(44) Stuchebryukov, S. D.; Selektor, S. L.; Silantieva, D. a.; Shokurov, a. V. Peculiarities of the Reflection Absorption and Transmission Spectra of Ultrathin Films under Normal Incidence of Light. Prot. Met. Phys. Chem. Surf. 2013, 49, 189-197.

(45) Faye, N. R.; Moroté, F.; Heywang, C. G.; Bouhacina, T. C. Oxidation of Langmuir-Blodgett Films of Monounsaturated Lipids Studied by Atomic Force Microscopy. Int. J. Nanotechnol. 2013, 10, 390-403.

(46) Gauthier, S.; Aimé, J. P.; Bouhacina, T.; Attias, A. J.; Desbat, B. Study of Grafted Silane Molecules on Silica Surface with an Atomic Force Microscope. Langmuir 1996, 12, 5126-5137.

(47) Ishikawa, N.; Okubo, T.; Kaizu, Y. Spectroscopic and Quantum Chemical Studies of Excited States of One and Two Electron Oxidation Products of a Lutetium Triple Decker Phthalocyanine Complex. Inorg. Chem. 1999, 38, 3173-3181.

(48) Gorbunova, Y.; Martynov, A.; Tsivadze, A. Crown Substituted Phthalocyanines: From Synthesis Towards Materials. In Handbook of Porphyrin Science; Kadish, K., Smith, K., Guilard, R., Eds.; World Scientific Publishing: Singapore, 2012; pp 271-388.

(49) Rousseau, R.; Aroca, R.; Rodriguez Mendez, M. L. Extended Hückel Molecular Orbital Model for Lanthanide Bisphthalocyanine Complexes. J. Mol. Struct. 1995, 356, 49-62.

(50) Bearden, J.; Burr, A. Reevaluation of X ray Atomic Energy Levels. Rev. Mod. Phys. 1967, 39, 125-142.

(51) Clementi, E. Atomic Screening Constants from SCF Functions. II. Atoms with 37 to 86 Electrons. J. Chem. Phys. 1967, 47, 13001307.

(52) Trifonov, A. A.; Fedorova, E. A.; Ikorskii, V. N.; Dechert, S.; Schumann, H.; Bochkarev, M. N. Solvent Mediated Redox Trans formations of Ytterbium Bis(indenyl)diazabutadiene Complexes. Eur. J. Inorg. Chem. 2005, 2005, 2812-2818.

(53) Trifonov, A.; Kurskii, Y. Diazabutadiene Derivatives of Ytterbocenes. Syntheses, Properties, and Crystal Structures of the $\left(\mathrm{C}_{5} \mathrm{Me}_{5}\right)_{2} \mathrm{Yb}$ (ButNCHCHNBut) and $\left[\mathrm{CpYb}\left(\mu_{2} \mathrm{OC}_{13} \mathrm{H}_{8} \mathrm{C}_{13} \mathrm{H}_{8} \mathrm{O}\right)\right.$. Russ. Chem. Bull. 2003, 52, 601-606.

(54) Naumkin, A.; Kraut Vass, A.; Gaarenstroom, S. W.; Powell, C. NIST X ray Photoelectron Spectroscopy Database, 2012; http:// srdata.nist.gov/xps/.

(55) Praline, G.; Koel, B. E.; Hance, R. L.; Lee, H. I.; White, J. M. X ray Photoelectron Study of the Reaction of Oxygen with Cerium. J. Electron Spectrosc. Relat. Phenom. 1980, 21, 17-30.

(56) Barr, T. L.; Fries, C. G.; Cariati, F.; Bart, J. C. J.; Giordano, N. A Spectroscopic Investigation of Cerium Molybdenum Oxides. J. Chem. Soc., Dalton Trans. 1983, 1825-1829. 